\title{
Reliability of digital panoramic radiography in the diagnosis of carotid artery calcifications*
}

\author{
Confiabilidade da radiografia panorâmica digital no diagnóstico de calcificações na artéria carótida
}

\author{
Vilson Lacerda Brasileiro Junior ${ }^{1}$, Aníbal Henrique Barbosa Luna ${ }^{2}$, Marcelo Augusto Oliveira de Sales ${ }^{2}$, \\ Tânia Lemos Coelho Rodrigues ${ }^{3}$, Priscilla Lopes da Fonseca Abrantes Sarmento ${ }^{4}$, Carlos Fernando \\ de Mello Junior ${ }^{5}$
}

Brasileiro Junior VL, Luna AHB, Sales MAO, Rodrigues TLC, Sarmento PLFA, Mello Junior CF. Reliability of digital panoramic radiography in the diagnosis of carotid artery calcifications. Radiol Bras. 2014 Jan/Fev;47(1):28-32.

Abstract Objective: The present study evaluated the reliability of digital panoramic radiography in the diagnosis of carotid artery calcifications. Materials and Methods: Thirty-five patients under high-risk for development of carotid artery calcifications who had digital panoramic radiography were referred to undergo ultrasonography. Thus, 70 arteries were assessed by both methods. The main parameters utilized to evaluate the panoramic radiography reliability in the diagnosis of carotid artery calcifications were accuracy, sensitivity, specificity and positive predictive value of this method as compared with ultrasonography. Additionally, the McNemar's test was utilized to verify whether there was a statistically significant difference between digital panoramic radiography and ultrasonography.

Results: Ultrasonography demonstrated carotid artery calcifications in 17 (48.57\%) patients. Such individuals presented with a total of $29(41.43 \%)$ carotid arteries affected by calcification. Radiography was accurate in $71.43 \%(n=50)$ of cases evaluated. The degree of sensitivity of this method was $37.93 \%$, specificity of $95.12 \%$ and positive predictive value of $84.61 \%$. A statistically significant difference $(p<0.001)$ was observed between the methods evaluated in their capacity to diagnose carotid artery calcifications.

Conclusion: Digital panoramic radiography should not be indicated as a method of choice in the investigation of carotid artery calcifications.

Keywords: Carotid artery calcification; End-stage renal disease; Panoramic radiography; Ultrasonography.

Resumo Objetivo: 0 presente estudo avaliou a confiabilidade da radiografia panorâmica digital no diagnóstico de calcificações na artéria carótida.

Materiais e Métodos: Trinta e cinco pacientes de alto risco para o desenvolvimento de calcificações na artéria carótida que tinham a radiografia panorâmica digital foram encaminhados para realização do exame de ultrassonografia. Assim, 70 artérias foram avaliadas pelos dois exames. Os principais parâmetros utilizados para avaliar a confiabilidade da radiografia panorâmica no diagnóstico de calcificações na artéria carótida foram a precisão, a sensibilidade, a especificidade e o valor preditivo positivo desse método quando comparado à ultrassonografia. Além disso, o teste de McNemar foi utilizado para verificar se existia diferença estatisticamente significante entre a radiografia panorâmica digital e ultrassonografia.

Resultados: De acordo com a ultrassonografia, 17 (48,57\%) pacientes apresentavam calcificações na artéria carótida. Esses indivíduos apresentavam um total de 29 (41,43\%) artérias carótidas atingidas por calcificações. 0 exame radiográfico foi preciso em acertar $71,43 \%$ ( $n=50$ ) dos casos avaliados. 0 grau de sensibilidade desse método foi 37,93\%, especificidade de 95,12\% e valor preditivo positivo de $84,61 \%$. Além disso, foi verificada diferença estatisticamente significante $(p<0,001)$ entre os exames avaliados na capacidade de diagnosticar calcificações na artéria carótida.

Conclusão: A radiografia panorâmica digital não deve ser indicada como exame de excelência para investigação da presença de calcificações na artéria carótida.

Unitermos: Calcificação na artéria carótida; Estágio final da doença renal; Radiografia panorâmica; Ultrassonografia.

* Study developed at Universidade Federal da Paraíba (UFPB), João Pessoa, PB, Brazil.

1. Master, Fellow PhD degree in Oral Pathology, Universidade Federal do Rio Grande do Norte (UFRN), Natal, RN, Associate Professor, Centro Universitário de João Pessoa (Unipê), João Pessoa, PB, Brazil.

2. PhDs, Associate Professors, Department of Clinical Practice and Social Odontology, Universidade Federal da Paraíba (UFPB), João Pessoa, PB, Brazil.

3. PhD, Associate Professor, Department of Clinical Practice and Social Odontology, Universidade Federal da Paraíba (UFPB), João Pessoa, PB, Brazil.

4. Master, Physician Assistant at Division of Vascular Doppler Ultrasonography, Centro de Treinamento em Imagenologia (Cetrim), João Pessoa, PB, Brazil.

5. PhD, Associate Professor, Department of Medicine, Universidade Federal da Paraíba (UFPB), João Pessoa, PB, Brazil.

\section{INTRODUCTION}

Atherosclerosis is a chronic inflammatory disease of multifactorial origin, characterized by artery walls thickening or elasticity loss, many times associated with presence of atheromas. Atheromas are plaques that may calcify, caused by ac-

Mailing Address: Dr. Vilson Lacerda Brasileiro Junior. Avenida Epitácio Pessoa, 4595, ap. 401A, Tambaú. João Pessoa, PB, Brazil, 58039-000. E-mail: vilsonjnr@ hotmail.com.

Received December 18, 2012. Accepted after revision August 14, 2013. 
cumulation of lipids or fibrous tissue in blood vessels ${ }^{(1-3)}$ As carotid arteries are affected by atheromas, stenosis of the vessel's lumen occurs, which considerably increases the risk for development of stroke ${ }^{(4)}$.

It is estimated that strokes represent the third cause of deaths in most countries worldwide ${ }^{(5)}$. Additionally, it is one of the main causes of long term physical disability. Thus, such condition may considered a significant public health problem, not only because of its incidence, but also because of the high costs involved in physical and psychological rehabilitation of the patients ${ }^{(6)}$.

With a view on this problem, all measures aimed at preventing atherosclerosis and methods to allow an early diagnosis in patients at high risk for stroke constitute the main resources for decreasing the prevalence of such a disease.

Currently, carotid ultrasonography (US) is the noninvasive imaging method utilized as the gold standard in the diagnosis of carotid artery calcification $(\mathrm{CAC})^{(7,8)}$, but it is not routinely performed in patients at risk for developing vascular calcifications. Thus, exams performed with a higher frequency in such patients, contributing for the initial diagnosis of CAC represent relevant life-saving sources of information.

In such a context, several studies report that CACs may be detected at panoramic radiography ${ }^{(4,9-14)}$. In dental practice, panoramic radiography is a routine imaging technique which provides wide anatomical coverage on a single image.

Radiographically, images suggestive of carotid artery atheromas are seen as radiopaque nodular masses or as diffuse, multiple nodules with vertical, linear distribution, frequently located close to the cervical vertebrae, at the level of the C3-C4 intervertebral junction ${ }^{(15-18)}$. Despite the clinical relevance of such radiographic finding, most scientific papers have sought to evaluate the prevalence of CACs in the general population, while only few investigations focused on the reliability of such method for the diagnosis of such lesions.

Thus the present study was aimed at evaluating the reliability of digital panoramic radiography (DPR) in the diagnosis of CACs.

\section{MATERIALS AND METHODS}

The present study was approved by the Committee for Ethics in Research of Hospital Universitário Lauro Wanderley, João Pessoa, PB, Brazil, under number 467/10. The study population included individuals presenting with chronic kidney disease, submitted to hemodialysis at reference nephrology centers in the city of João Pessoa, Paraíba, Brazil, who sought the Dental Service of Universidade Federal da Paraíba in the period between January and November/2011. Those patients who, on the course of their first visit, required DPR for the planning of oral rehabilitation, were included in the present study after signing a term of free and informed consent.

The authors have opted for studying individuals with chronic kidney disease based on the fact that CACs are one of the most severe and frequent complications in this group of patients ${ }^{(19)}$. Such complications occur because metabolic changes in chronic kidney disease produce an increase in the amount of promoters of calcification, resulting in the development of a higher number of vascular calcifications ${ }^{(20)}$.

At the end of the data collection period, 50 DPRs were obtained from nephropathic patients with ages between 18 and 60 years and undergoing hemodialysis for at least one year. All DPRs included in the present study were obtained by means of a Kodak 9000C 3D apparatus (Carestream Health; Rochester, USA), operating in the range of 64-74 $\mathrm{kV}, 8-10 \mathrm{~mA}$ with exposure times ranging between 13 and 15.1 seconds, according to patients' size. After acquisition, the images were stored in the TIFF format (without compression), with a mean resolution of $2700 \times 1530$ pixels, on a workstation connected with the radiographic apparatus. Later, the images were analyzed by a radiologist in the "full screen" mode on a widescreen LCD AOC 22" display with a maximum resolution of $1680 \times 1050$ pixels. The evaluation of the images was performed in a room with appropriate lighting, allowing adjustments in contrast, brightness and magnification by the investigator in order to provide the best possible visualization.

The presence of radiopaque nodules in the soft tissue region adjacent to the cervical vertebrae $\mathrm{C} 3$ and $\mathrm{C} 4$, was considered as being a suggestive of CAC (Figure 1). Additionally, differential diagnosis was performed with anatomical structures or diseases which might be present in the evaluated area. During the analysis of the images, the unilaterality or bilaterality of the CAC images were recorded.

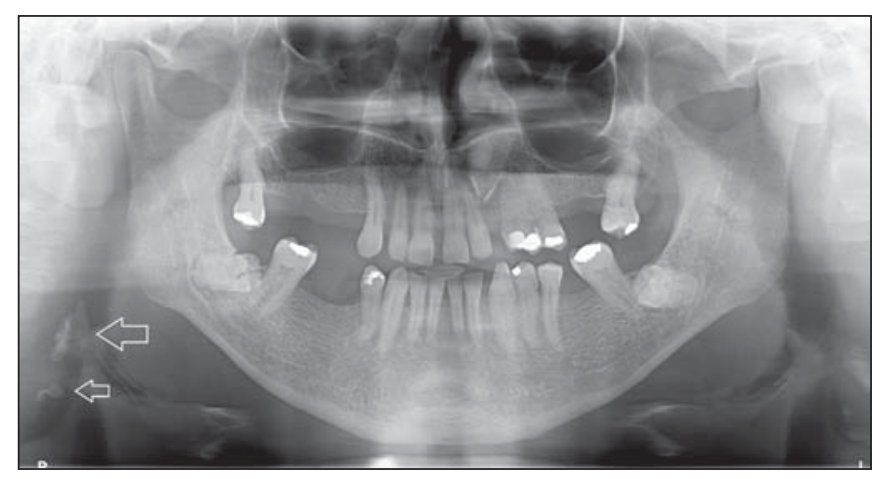

Figure 1. DPR image suggesting the presence of carotid artery calcifications.

After the DPR images acquisition, the 50 patients were invited to undergo carotid US scan, but 15 patients did not return and were excluded from the study. Such a scan was bilaterally performed in order to confirm the presence of CAC, seeking to visualize the common carotid, internal and external carotid arteries (Figure 2). The US scans were performed by an experienced radiologist, utilizing a Medison SonoAce X8 (Medison; Seoul, South Korea) apparatus equipped with a 7-10 MHz linear transducer. Sonographic grayscale images acquisition was followed by color Doppler scans. The structures presenting hyperechoic signal, with 


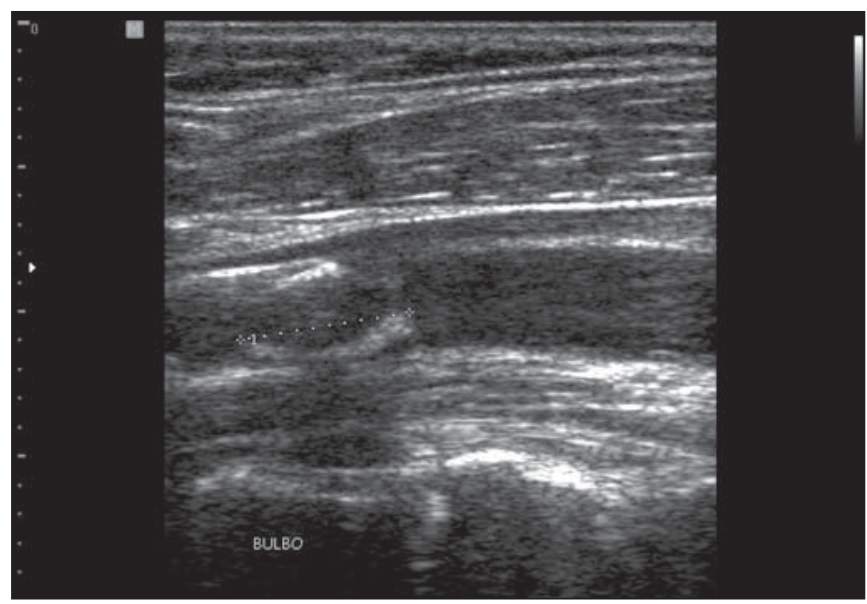

Figure 2. Carotid artery calcification detected at ultrasonography.

distal acoustic shadows in the examined vessels were considered as being atheroma images. The radiologist was blinded to the conclusions obtained from panoramic radiography.

The degree of stenosis caused by CACs was subsequently analyzed. The stenoses were classified according to the criteria from the North American Symptomatic Carotid Endarterectomy Trial ${ }^{(21)}$, as follows: non-hemodynamically significant (obstruction $<50 \%$ ) and hemodynamically significant (obstruction $>50 \%$ ). Patients with vessels' lumen obstruction $>70 \%$ were considered as critical stenosis cases.

The data obtained from the exams were organized and submitted to statistical analysis. The main parameters utilized in the evaluation of DPR reliability in the diagnosis of CAC were accuracy, sensitivity, specificity and positive predictive value (PPV) of the method, as compared with US. That is because the sensitivity of a method is related to the capacity of identifying the individuals who present with the disease (CAC diagnosed at US) and have positive results in the evaluated method (DPR). The above mentioned parameters are expressed in percentages ranging from 0 to 100 , depending on the results observed.

Additionally, it was also verified whether there was any statistically significant difference between DPR and US in the diagnosis of CAC. For such an evaluation, the McNemar's test was utilized, with a significance level of $5 \%(p<0.05)$.

\section{RESULTS}

The present study included 35 chronic renal patients who underwent both DPR and US scans. Among such patients, $18(51.43 \%)$ were men and $17(48.57 \%)$ were women. Their mean age was $41.17( \pm 10.99)$ years and the mean time under hemodialysis treatment was $6.06( \pm 4.02)$ years. Each patient was bilaterally examined, resulting in a final sample of 70 evaluated arteries.

US revealed that 17 patients $(48.57 \%)$ presented with $\mathrm{CAC}$, with ten of those patients being men $(58.82 \%)$ and seven being women (41.18\%). Among such individuals, 12 $(70.59 \%)$ presented with bilateral lesions, while $5(29.41 \%)$ patients presented with unilateral calcifications (four located at the right side and one on the left side). Thus, a total of 29 $(41.43 \%)$ carotid arteries presented with calcifications. Such calcifications caused hemodynamically significant stenosis in only one $(3.45 \%)$ of the evaluated arteries.

The radiographic findings demonstrated that nine patients $(25.71 \%)$ had images suggestive of the presence of CACs, and five of such patients had only right-sized lesions and four, bilateral lesions. Thus, 13 arteries (18.57\%) were radiographically diagnosed as being affected by CAC.

As DPR and US results were compared, it was observed that only $11(37.93 \%)$ out the 29 CACs detected at US were correctly diagnosed at radiography, resulting in a low sensitivity level of the evaluated method. On the other hand, 11 $(84.61 \%)$ out 13 arteries whose calcification was detected at radiography were confirmed at US, which demonstrates a good PPV. Also, at US, it was observed that 41 arteries did not present calcifications, $39(95.12 \%)$ of them considered to be free from CACs at radiography, a fact that demonstrates a high specificity of the evaluated method. Finally, a statistically significant $(p<0.001)$ difference was observed between the evaluated methods as regards their capability to diagnose CACs.

Therefore, one can assert that radiography was accurate in $71.43 \%(n=50)$ of the cases. The level of sensitivity of the method was $37.93 \%$; the specificity, $95.12 \%$; and PPV was $84.61 \%$.

\section{DISCUSSION}

The presence of atheromas in the carotid arteries of neurologically asymptomatic individuals is frequently associated with future development of cerebrovascular diseases ${ }^{(22)}$. Unfortunately, late diagnosis of such lesions is observed in many cases and stroke is the first clinical manifestation occurring in patients affected by $\mathrm{CAC}^{(23)}$. The routine performance of exams in the head and neck region which might help in the diagnosis of CACs in the early stages of development would be a form of preventing such a severe manifestation. According to Mupparapu et al. ${ }^{(24)}$, panoramic radiography is very frequently utilized in the dental practice, involves the carotid artery region and has frequently been reported as a method capable of detecting CAC.

However, for a correct diagnosis, the professional responsible for the analysis of the radiographic image must be able to identify anatomic structures and pathological soft tissue calcifications present in the head and neck region which make up the differential diagnosis with CACs. The main radiopacities which may be confused with CACs during image observation correspond to calcified lymph nodes, sialoliths, phleboliths, hyoid bone, calcification of the styloid and stylomandibular ligaments, as well as those of the triticeal, cricoid and thyroid cartilages ${ }^{(11,25,26)}$.

The clinical importance of such a radiographic finding is so high that the dental literature recommends that patients whose images suggest the presence of CACs be referred for 
cardiovascular evaluation ${ }^{(13,27,28)}$. However, before referring the patient for medical evaluation, the dental surgeon should consider the accuracy, sensitivity, specificity and PPV of the radiographic image for the diagnosis of CACs. Such parameters define the level of reliability of such method for the diagnosis of calcifications.

In recent years, studies published in the literature have demonstrated a wide variation in the panoramic radiography reliability for the diagnosis of CAC. Ertas et al. ${ }^{(9)}$, evaluating such a reliability, have compared DPR findings with those from US, and reported that radiography was accurate in the detection of the lesions in $82 \%$ of cases, with a high level of sensitivity $(71 \%)$ and specificity $(87 \%)$ for the diagnosis of CAC. However, different results were reported by Madden et al. ${ }^{(7)}$ who compared panoramic radiography data with US data and observed that radiography, in spite of its high specificity $(87.5 \%)$ and good PPV $(78.7 \%)$, presented low sensitivity $(31.1 \%)$ in the diagnosis of CACs.

With a different study method, Yoon et al. ${ }^{(29)}$ have compared the results obtained by panoramic radiography and those obtained by computed tomography. Those authors assert that radiography was accurate in the diagnosis of CACs in $62.3 \%$ of cases, with a sensitivity of $22.2 \%$, specificity of $90 \%$ and PPV of $60.6 \%$. Such authors have concluded that radiography presented a moderate capability of detecting CACs.

The present study found results that are close to those described by Yoon et al. ${ }^{(29)}$, observing that DPR was accurate in the diagnosis of $71.43 \%$ of the evaluated CAC cases, with low sensitivity $(37.93 \%)$, high specificity $(95.12 \%)$ and good PPV (84.61\%). According to Almog et al. ${ }^{(30)}$, such a low sensibility of the radiographic method is probably more related to the level of calcification of some atherosclerotic plaques than to the fact that the exam may not have been properly performed.

In spite of the low sensitivity of DPR observed in the present study, the method presented a good PPV (84.61\%) in the diagnosis of CACs, which demonstrates its potential in detecting such lesions. Additionally, it is important to highlight that $96.55 \%$ of the evaluated arteries did not present with hemodynamically significant stenosis. In other words, radiography detected not only lesions in advanced stages of vessel obstruction.

The present study results also revealed a statistically significant difference $(p<0.001)$ between DPR and US with respect to the capability of diagnosing CAC. Thus, one can assert that there was not a high index of agreement between the two methods in the diagnosis of CACs. Such result was different from that reported by Romano-Sousa et al. ${ }^{(4)}$ who found a high agreement level between the two methods in this type of evaluation.

Therefore, one can conclude that DPR presents a moderate accuracy, high specificity and low sensitivity in the diagnosis of CACs. Additionally, its results were significantly different from those observed at US in the diagnosis of such lesions. Thus, DPR should not be indicated as a method of excellence to investigate the presence of this type of calcification.

However, the good PPV demonstrated by DPR in the diagnosis of CAC allows the authors to assert that such method may contribute for the detection of such lesions in asymptomatic patients. Thus, patients whose DPR images are suggestive of CAC should be referred for specialized medical evaluation.

\section{REFERENCES}

1. Kurnatowska I, Grzelak P, Stefanczyk L, et al. Tight relations between coronary calcification and atherosclerotic lesions in the carotid artery in chronic dialysis patients. Nephrology (Carlton). 2010;15:184-9.

2. Guimarães Henriques JC, Kreich EM, Helena Baldani M, et al. Panoramic radiography in the diagnosis of carotid artery atheromas and the associated risk factors. Open Dent J. 201 1;5:79-83.

3. Gelev S, Spasovski G, Dzikova S, et al. Vascular calcification and atherosclerosis in hemodialysis patients: what can we learn from the routine clinical practice? Int Urol Nephrol. 2008;40:763-70.

4. Romano-Sousa CM, Krejci L, Medeiros FM, et al. Diagnostic agreement between panoramic radiographs and color Doppler images of carotid atheroma. J Appl Oral Sci. 2009;17:45-8.

5. Fatahzadeh M, Glick M. Stroke: epidemiology, classification, risk factors, complications, diagnosis, prevention, and medical and dental management. Oral Surg Oral Med Oral Pathol Oral Radiol Endod. 2006;102:180-91.

6. Uthman AT, Al-Saffar AB. Prevalence in digital panoramic radiographs of carotid area calcification among Iraqi individuals with stroke-related disease. Oral Surg Oral Med Oral Pathol Oral Radiol Endod. 2008;105:e68-73.

7. Madden RP, Hodges JS, Salmen CW, et al. Utility of panoramic radiographs in detecting cervical calcified carotid atheroma. Oral Surg Oral Med Oral Pathol Oral Radiol Endod. 2007;103:543-8.

8. Johnson M, Wilkinson ID, Wattam J, et al. Comparison of Doppler ultrasound, magnetic resonance angiographic techniques and catheter angiography in evaluation of carotid stenosis. Clin Radiol. 2000;55:912-20.

9. Ertas ET, Sisman Y. Detection of incidental carotid artery calcifications during dental examinations: panoramic radiography as an important aid in dentistry. Oral Surg Oral Med Oral Pathol Oral Radiol Endod. 2011;112:e11-7.

10. Johansson EP, Ahlqvist J, Garoff M, et al. Ultrasound screening for asymptomatic carotid stenosis in subjects with calcifications in the area of the carotid arteries on panoramic radiographs: a cross-sectional study. BMC Cardiovasc Disord. 2011;11:44.

11. Christou P, Leemann B, Schimmel M, et al. Carotid artery calcification in ischemic stroke patients detected in standard dental panoramic radiographs - a preliminary study. Adv Med Sci. 2010;55:2631 .

12. Kansu O, Ozbek M, Avcu N, et al. Can dental pulp calcification serve as a diagnostic marker for carotid artery calcification in patients with renal diseases? Dentomaxillofac Radiol. 2009;38:5425.

13. Gokce C, Sisman Y, Sipahioglu M, et al. The prevalence of carotid artery calcification on the panoramic radiographs of end-stage renal disease patients with peritoneal dialysis: do incidental findings provide life-saving information? J Int Med Res. 2008;36:47-53.

14. Kansu O, Ozbek M, Avcu N, et al. The prevalence of carotid artery calcification on the panoramic radiographs of patients with renal disease. Dentomaxillofac Radiol. 2005;34:16-9.

15. Pornprasertsuk-Damrongsri S, Virayavanich W, Thanakun S, et al. The prevalence of carotid artery calcifications detected on panoramic 
radiographs in patients with metabolic syndrome. Oral Surg Oral Med Oral Pathol Oral Radiol Endod. 2009;108:e57-62.

16. Beckstrom BW, Horsley SH, Scheetz JP, et al. Correlation between carotid area calcifications and periodontitis: a retrospective study of digital panoramic radiographic findings in pretreatment cancer patients. Oral Surg Oral Med Oral Pathol Oral Radiol Endod. 2007;103:359-66.

17. Kumagai M, Yamagishi T, Fukui N, et al. Long-term cigarette smoking increases the prevalence of carotid artery calcification seen on panoramic dental radiographs in male patients. Tohoku J Exp Med. 2007;212:21-5.

18. Sisman Y, Ertas ET, Gokce C, et al. The prevalence of carotid artery calcification on the panoramic radiographs in Cappadocia region population. Eur J Dent. 2007;1:132-8.

19. Luczak M, Formanowicz D, Pawliczak E, et al. Chronic kidney disease-related atherosclerorosis - proteomic studies of blood plasma. Proteome Sci. 2011;9:25.

20. Schiffrin EL, Lipman ML, Mann JF. Chronic kidney disease: effects on the cardiovascular system. Circulation. 2007;116:85-97.

21. North American Symptomatic Carotid Endarterectomy Trial Collaborators. Beneficial effect of carotid endarterectomy in symptomatic patients with high-grade carotid stenosis. N Engl J Med. 1991; 325:445-53.

22. Friedlander AH, Cohen SN. Panoramic radiographic atheromas portend adverse vascular events. Oral Surg Oral Med Oral Pathol Oral Radiol Endod. 2007;103:830-5.

23. Almog DM, Horev T, Illig KA, et al. Correlating carotid artery steno- sis detected by panoramic radiography with clinically relevant carotid artery stenosis determined by duplex ultrasound. Oral Surg Oral Med Oral Pathol Oral Radiol Endod. 2002;94:768-73.

24. Mupparapu M, Kim IH. Calcified carotid artery atheroma and stroke: a systematic review. J Am Dent Assoc. 2007;138:483-92.

25. Damaskos S, Griniatsos J, Tsekouras N, et al. Reliability of panoramic radiograph for carotid atheroma detection: a study in patients who fulfill the criteria for carotid endarterectomy. Oral Surg Oral Med Oral Pathol Oral Radiol Endod. 2008;106:736-42.

26. Kamikawa RS, Pereira MF, Fernandes A, et al. Study of the localization of radiopacities similar to calcified carotid atheroma by means of panoramic radiography. Oral Surg Oral Med Oral Pathol Oral Radiol Endod. 2006;101:374-8.

27. Pornprasertsuk-Damrongsri S, Thanakun S. Carotid artery calcification detected on panoramic radiographs in a group of Thai population. Oral Surg Oral Med Oral Pathol Oral Radiol Endod. 2006; 101:110-5.

28. Friedlander AH, Garrett NR, Chin EE, et al. Ultrasonographic confirmation of carotid artery atheromas diagnosed via panoramic radiography. J Am Dent Assoc. 2005;136:635-40.

29. Yoon SJ, Yoon W, Kim OS, et al. Diagnostic accuracy of panoramic radiography in the detection of calcified carotid artery. Dentomaxillofac Radiol. 2008;37:104-8.

30. Almog DM, Illig KA, Carter LC, et al. Diagnosis of non-dental conditions. Carotid artery calcifications on panoramic radiographs identify patients at risk for stroke. N Y State Dent J. 2004;70:20 5. 